\title{
Digital Tailings System for Non-coal Mine Solid Waste Safety Treatment
}

\section{Quan-ming 1,2,a , ZHANG Hong ${ }^{2, b}$, YANG Zhao ${ }^{2, c}$}

\author{
${ }^{1}$ China Academy of Safety and Science \& Technology, Beijing, China, 100012 \\ ${ }^{2}$ North China Institute of Science \& Technology, Langfang, China, 101601 \\ a454968503@qq.com, b1359243783@qq.com, c1690814870@qq.com
}

\begin{abstract}
Keywords: Digital tailings ponds; Tailings ponds; Solid waste treatment
Abstract. Tailings pond is an important basic facility in mine production. Its safety operation is not only related to the normal production and operation of enterprises, but also has important influence on the life and property safety and ecological environment of people in the downstream and surrounding areas. It's challenges for the traditional tailings pond management that tailings pond accidents frequently in recent years. Digital tailings project refers to the tailings pond theory as the support and tailings data warehouse as operation object, with using full digital measurement, remote sensing, geographic information system and global positioning system and other modern methods based data acquisition, realize the tailings by terrain, hydrology and meteorology, monitoring, flood, tailings dam stability, risk analysis, the function such as facilities management, emergency training the organic integration of corporate control platform. In this paper, a large-scale valley-type tailings pond is taken as an example to establish a digital tailings system which can realize the warning of large-scale valley-type tailings ponds, which can greatly improve the safety and security level of tailings in China. It has great significance to realize the social harmonious development and the harmonious development of society.
\end{abstract}

\section{Introduction}

Tailings dam refers to the dam blocking the valley mouth or the formation of the surrounding, used to store metal and non-metallic mineral ore sorting tailings or other industrial waste residue after the place ${ }^{[1]}$. According to "Design Specification for Tailings Facilities" (GB50863-2013) and "Technical Regulations for Safety of Tailings Depot" (AQ2006-2005), tailings banks of third class and above in China must establish an on-line monitoring system for tailings ponds. Should install online monitoring system. As of the end of 2015, China had 1168 tailings ponds installed on-line monitoring system. At present, there are some problems in the on-line monitoring system of tailings depot in our country, such as the lack of stability of some monitoring equipments, the unsuitable setting of monitoring points, the failure of timely analysis of monitoring data and the poor matching of management schemes with on-site conditions. System and security management poses challenges. In 2004, Wang et al first proposed the preliminary framework of the digital tailing pond system ${ }^{[2]}$. In 2011, Li Qingshi et al. Described the monitoring methods of displacement, saturation line and rainfall [3]. In 2014, Liao et al. Developed a real-time monitoring of tailings and safety analysis of early warning coupled model ${ }^{[4]}$. Digital tailings reservoir refers to the tailings reservoir theory as a support to tailings warehouse data warehouse for the operation of the object, with the help of all digital measurement, remote sensing, geographic information system or global positioning system and other modern means of collecting basic data to achieve tailings reservoir topography The integrated management and control platform integrating topography, hydrometeorology, monitoring and control, flood control, stability of tailings dam, risk analysis, equipment and facility management, emergency training and other functions can provide reliable security support for mine production and surrounding community stability ${ }^{[5]}$.

In this paper, taking the more dangerous valley-shaped tailing pond as an example, a digital tailings pond system that can realize early warning of large-scale valley tailings ponds is established, which can greatly improve the level of safety of tailings ponds in our country. It is of great significance for the society around the mines to be stable and realize the harmonious development of the society. 


\section{Establishment of digital tailing ponds}

In this paper, a valley tailings in China as an example, the number of tailings pond system construction. The tailings depot belongs to the low mountainous area. The "V" shaped valley is developed. The slope of the mountain ranges from $30^{\circ}$ to $40^{\circ}$. It is mostly covered by thin-layer Quaternary system and the vegetation is shrub-dominated. The initial dam crest elevation of $505 \mathrm{~m}$, dam height of $33 \mathrm{~m}$, slope ratio of $1: 2$, the total storage capacity of $2210.5 \times 104 \mathrm{~m}^{3}$, is a third-class library.

Based on the establishment of a three-dimensional digital tailing pond platform, the valley-type digital tailings pond system has been built to include on-line monitoring of tailings ponds, safety management, vehicle positioning and dispatching, emergency management and training, flood regulation calculation, stable and real- 10 subsystems including systems for analyzing and quantifying early warning of disasters, risk analysis of dam failure, equipment operation status and so on, realizing on-site display, flood control calculation, on-line monitoring system and early warning, dam stability analysis, safety management, accident risk Analysis, system settings and user management 8 major functions. The system can set the parameters of tailings dam height, slope ratio, dry-beach length, dry-beach slope, rock-soil physical parameters, operating conditions and so on. According to the characteristics of tailings reservoir such as topography, geology and climate, Working conditions and tailings under the conditions of the actual situation and the scene, and tailings for different operating conditions under the conditions of possible major accidents issued by the pertinent and operational emergency plans and on-site disposal programs. The system uses a 3D engine to support real-time simulation of 3D scenes with millions of model faces and large amounts of data, and can simulate various natural weather conditions such as raining and snowing to support lifelike watermark effects on special effects as well as Perfect physics engine support.

The flood control subsystem in this system can display the real-time data of monitoring water regimes, rain conditions and working conditions in the 3D digital tailings database. The information query subsystem can query the historical data of water and rain events in the tailings pond area, And can be displayed in two-dimensional and three-dimensional GIS diagrams in a variety of visual forms such as dynamically changing line charts. The flood control calculation subsystem can calculate the flood process of the tailing pond according to different working conditions, Adjust the process of future flood into the reservoir, such as zooming in and out of the reservoir flood process, zoom in and out of storage flood peak, adjust the flood peak time, and in accordance with the tailings flood control and flood control effect, produce the best forecast program and the most dangerous conditions forecast Program to enhance the safety management of tailings ponds. Flooding calculation model is the core of this system calculation. Based on the principle of tailings reservoir water balance, this model will invoke the built-in flood discharge capacity and water level calculation module to calculate the flood control. According to the calculation result of the water forecasting module, the water level calculation module and the flood releasing module are recirculated to calculate the flood discharging process, the storage capacity process, the water level process and the safe beach head length process of the tailings pond, and the maximum water level, the minimum safety beach head length and the corresponding Time appears.

Software uses panoramic roaming mode, the use of keyboard and mouse for roaming operation control, all-round observation of tailings monitoring the actual situation of each location. In order to increase the flexibility of the system, a parameter modification interface is provided, and the related parameters can be adjusted according to the actual situation of the tailings dam. In addition, the system implements log management, user management, backup and recovery functions to facilitate data management and output. 


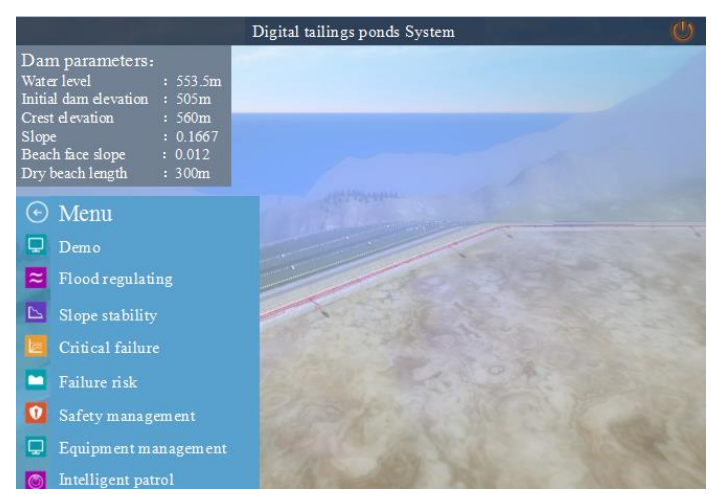

Figure 1. Digital tailings system interface

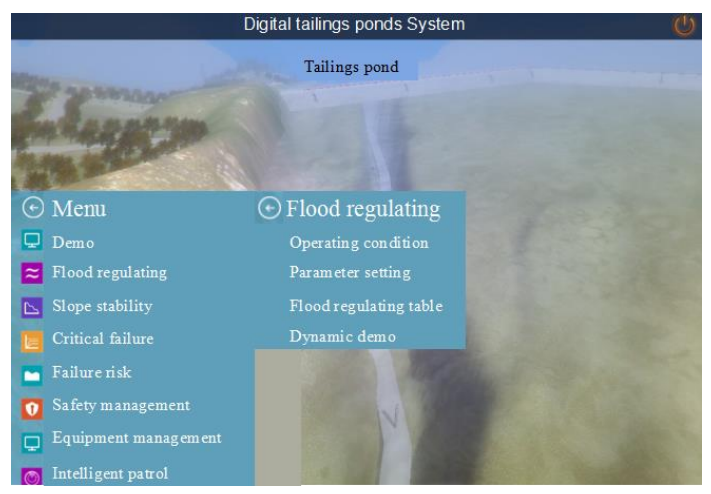

Figure 2. Flood Calculation Options module

Valley type digital tailings system interface shown in Figure 1. The system interface is divided into nine modules: live demonstration, flood calculation, dam stability analysis, critical dam analysis and treatment, safety management, equipment management, intelligent inspection and basic data, all of which are right-pull menus. Take flood control calculation as an example (as shown in Figure 2). The right-hand menu contains four options: calculation condition, parameter setting, flood adjustment calculation table and dynamic demonstration. Among them, the calculation conditions include 500 cases of flood conditions, "7.21" extraordinary flood conditions, 24-hour rainfall set conditions, the future weather conditions and actual rainfall conditions and other conditions of five kinds of conditions, the software It can output flood process curve, storage curve (VH relationship), flood discharge process curve and storage capacity curve of each flood condition, and carry out multi-directional flood prevention capability test for tailings ponds, which is used for equipment management of tailings pond in flood season, preparation of emergency plan , Provided a theoretical support for major hidden site disposal, to ensure the stability of the tailings dam flood season.

The system will be the enterprise safety management rules and regulations and equipment information into the monitoring and control within the scope of the formation of tailings closed-loop management. Enterprise personnel in the tailings site monitoring at the same time through the "safety management" option to view the enterprise production safety responsibility system, safety rules and regulations and operating procedures and other content, through the "equipment management" option for tailings of the equipment The detailed information and the operation status of the tailings pond can be effectively enhanced through the inspection by the "intelligent inspection" module in real time on the inspection conditions of the tailings ponds and the real-time operation status of the dam body, thereby effectively improving the safety management level of the tailings ponds, Management.

\section{Example calculation}

According to the characteristics of topography, geography and climate in the area where the tailing pond is located, this paper gives an example calculation on the flood control ability, stability and dam failure risk of the tailings pond.

flood regulation

The "Parameter Setting" module in "Flood Calculation" can set the actual reservoir level, interval time and interval of water level in the tailings dam (Figure 3). The "Working Condition Selection" module sets up five flood mechanics Condition, can verify the flood control ability of tailings reservoir in an all-round way. The valley level tailings reservoir reservoir water level elevation $553.5 \mathrm{~m}$, monitoring time frequency $0.02 \mathrm{~h}$, water level statistical frequency of $0.5 \mathrm{~m}$, select 500 flood cases as an example to calculate, the software will be based on background embedded in the historical data to calculate the work Rainfall, rainfall, rainfall and other data, and then calculate and give the tailings of the flood during the floodWater process curve and tailings drainage facilities, as shown in Figure 4. As can be seen from the figure, after the commencement of the working conditions, the flood discharge of the tailings dam has dramatically increased. After about $0.16 \mathrm{~h}$, the flood discharge reached the highest value of $101.612 \mathrm{~m}^{3} / \mathrm{s}$, and then the flood flow decreased gradually to 0 , taking $1.8443 \mathrm{~h}$. With the increase of flood flow, the water level of tailing ponds kept rising. The discharge of 
drainage facilities at different elevation gradually increased until reaching the maximum discharge of $12.4162 \mathrm{~m}^{3} / \mathrm{s}$. The software gives the free discharge, semi-pressure flow, pressure flow and the best discharge of four kinds of tailings discharge and discharge flow pattern of the drainage operation curve for the actual operation of tailings ponds, tailings discharge facilities The choice of ways to provide theoretical support. In order to effectively prevent the tailings dam from being overrun by dam failure, the system calculates the heavy rain, flood peak flow, flood in one working condition of 500 years, "7.21" flood accident and 24 hours rainfall in this reservoir area. Total, put forward tailings reservoir water level warning value, as shown in Table 1. In addition, the software provides a flood profile calculation table that can be used to view the dynamic simulation data of rainfall, reservoir water level elevation, drainage and other projects during various stages of rainfall in the working conditions. The demo module can directly view the dynamic demonstration videos of tailings reservoir rainfall process Fig.5).

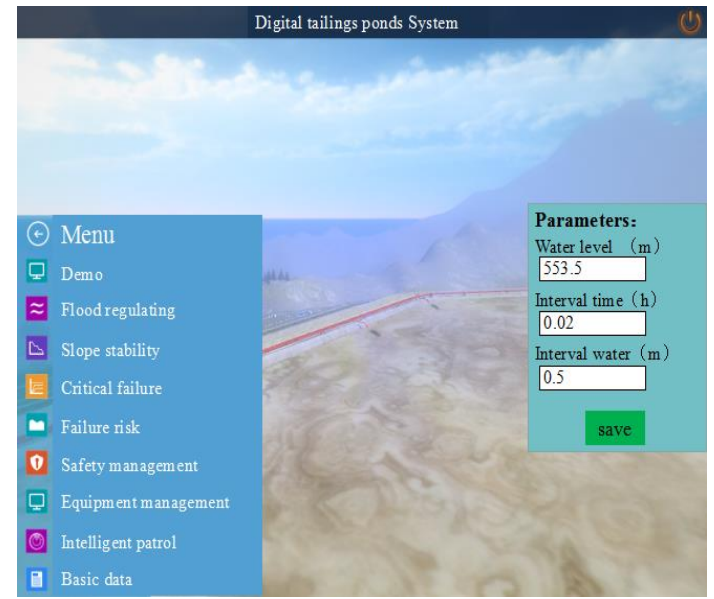

Figure.3. Parameter settings

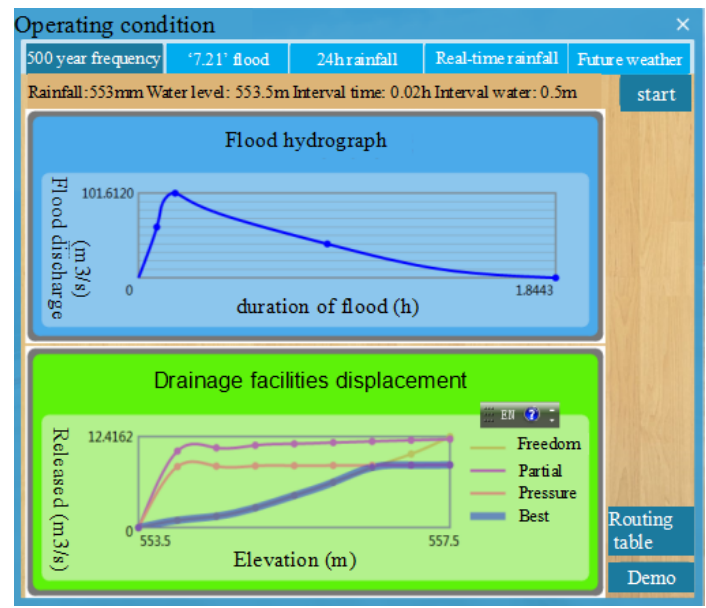

Figure.4. Flood season in flood conditions under the conditions of tailings ponds

Table.1 Tailings reservoir water level warning value

\begin{tabular}{|c|c|c|c|c|c|}
\hline $\begin{array}{c}\text { Warning } \\
\text { level }\end{array}$ & $\begin{array}{l}\text { flood } \\
\text { frequency }\end{array}$ & $\begin{array}{c}\text { Present } \\
\text { water level } \\
\text { (m) }\end{array}$ & $\begin{array}{l}\text { Maximum } \\
\text { flood rise }(\mathrm{m})\end{array}$ & $\begin{array}{c}\text { Dry beach } \\
\text { elevation } \\
\text { (m) }\end{array}$ & $\begin{array}{c}\text { Warning } \\
\text { water level } \\
(\mathrm{m})\end{array}$ \\
\hline III & $1 \%$ & 553.5 & 0.928 & 558 & 557.2 \\
\hline II & $0.5 \%$ & 553.5 & 0.815 & 558 & 557.4 \\
\hline I & $0.2 \%$ & 553.5 & 0.525 & 558 & 557.7 \\
\hline & & 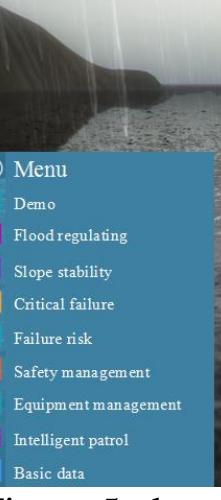 & simulation $s$ & 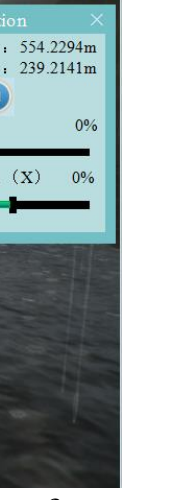 & \\
\hline
\end{tabular}

Figure.5. dynamic presentation interface

dam stability analysis

Numerical stability analysis of dam system in digital tailing dam embed finite element method and discrete element method two kinds of calculation module respectively, from the macro and micro aspects of the tailings reservoir landslide process of movement characteristics and laws, and through 
the strength reduction principle The strength of the tailings pond unit is gradually reduced to calculate the slope stability coefficient.

In 1971, Cundall ${ }^{[6,7]}$ proposed a discrete element method suitable for rock mechanics problems, and extended it to the analysis of meso-mechanics behavior of granular soil. The basic idea of Discrete Element Method is to decompose the discontinuity into a set of discrete elements. According to the actual situation, the unitary elements are chosen to contact the constitutive relation reasonably and satisfy the equations of motion. The equations of motion for each element are solved by the time-step iteration method and the overall motion pattern is obtained ${ }^{[8]}$.

Discrete element method is to use the central difference method for dynamic relaxation solution, which belongs to the explicit solution, the basic equation of motion is:

$$
\begin{aligned}
& m \ddot{x}(t)+c \dot{x}(t)+k x(t)=f(t) \\
& m-\text { unit quality; } \\
& x-\text { displacement; } \\
& t \text { - time; } \\
& c-\text { viscous damping coefficient } \\
& k-\text { stiffnesscoefficient; } \\
& f-\text { external load of the unit; }
\end{aligned}
$$

This method does not need to solve the large matrix, and allows the unit to have a great translation and rotation, the calculation is simple and convenient. It can be used to analyze the nonlinear problems such as the dam failure of tailings dam and the destruction of rock-soil slope ${ }^{[9]}$.

PFC2D is a software which simulates circular particle motion and its interaction through discrete element method (DEM) ${ }^{[10]}$. It has been widely used as a representative software of discrete element method and can be used to analyze the microscopic particles inside the dam during the tailings dam landslide The movement characteristics and evolution law, and the slope stability coefficient calculation.

Click on the "Dam Stability Analysis" button, select the discrete element method and enter the dam material partition number, crest elevation, reservoir water level elevation and other corresponding parameters after the slope stability coefficient calculation, as shown in Figure 6 . Software through the built-in PFC2D software, automatic simulation of dangerous sections of dam tailings dam, and by strength reduction method to calculate the value of the dam safety factor of 1.642 , as shown in Figure.7.

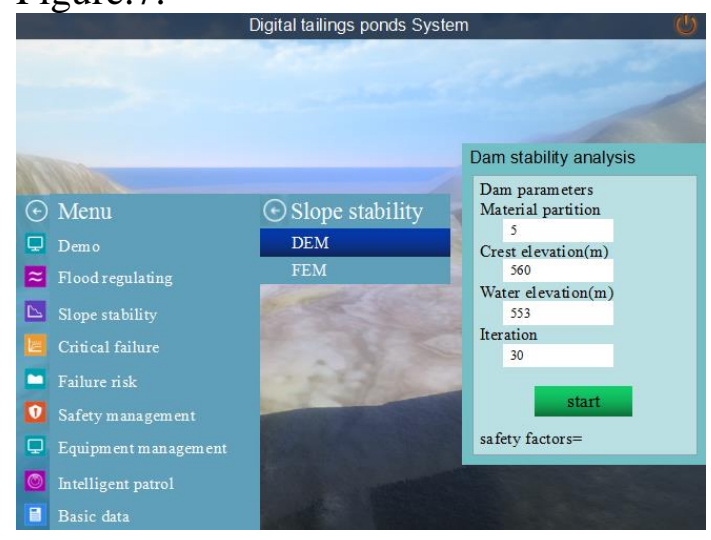

Fig.6. Slope stability analysis with DEM

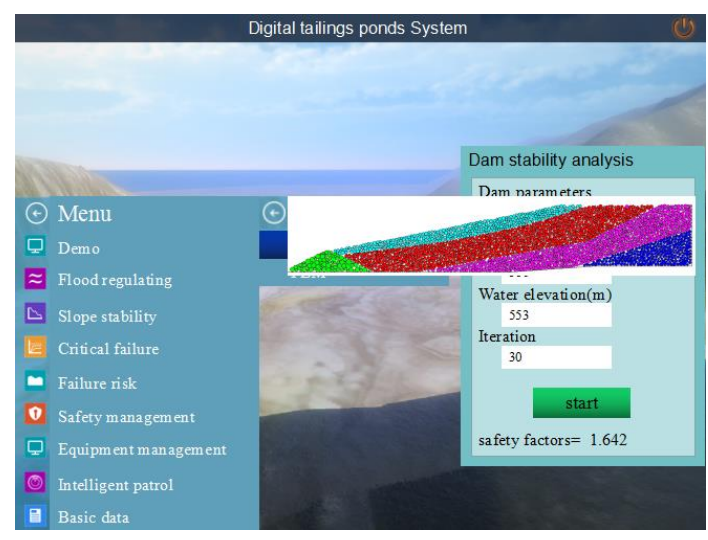

Figure.7. Discrete element method slope stability analysis

Dam failure risk analysis

"Dam risk analysis" module is mainly used to assess the severity of dam failure consequences. The maximum discharge of tailing sand after dam failure, the thickness of debris flow downstream of dam and the flooding range of dam break can be calculated by inputting the total reservoir capacity before failure, upstream water depth, dam height and length (Figure.8) in the parameter panel. The total storage capacity of the valley-type tailings dam before the dam collapse is $1500 \times 104 \mathrm{~m}^{3}$, the upstream water level is $3 \mathrm{~m}$, the height of the dam is $90 \mathrm{~m}$ and the length of the main dam is $900 \mathrm{~m}$. 
After calculation, it can be known that once the tailings dam collapses, $1515.57 \mathrm{~m}^{3} / \mathrm{s}$, and the thickness of debris flow at $3 \mathrm{~m}$ downstream of the dam is $3244.313 \mathrm{~m}$. Click on the "View contours" option to see the submerged area and submerged depth of the tailings dam after dam failure (Figure.9) "The module can watch the whole process of tailing dam dam break and the impact on the downstream.

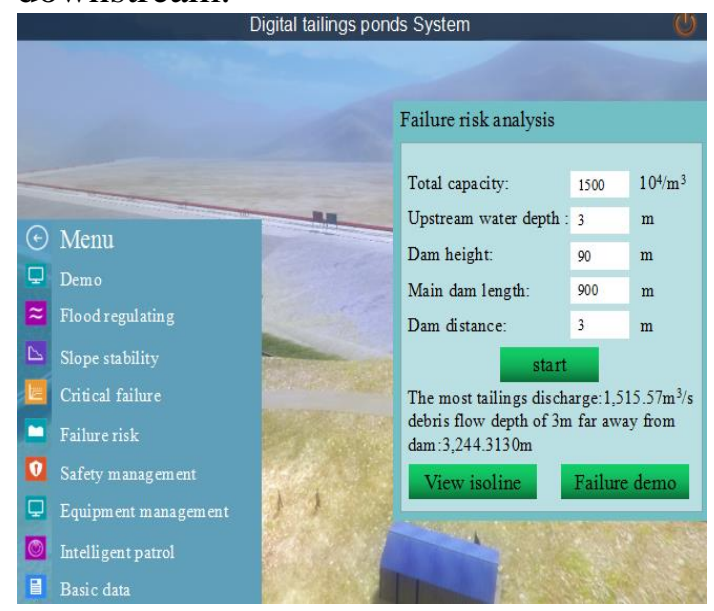

Figure.8 Dam failure analysis and calculation interface

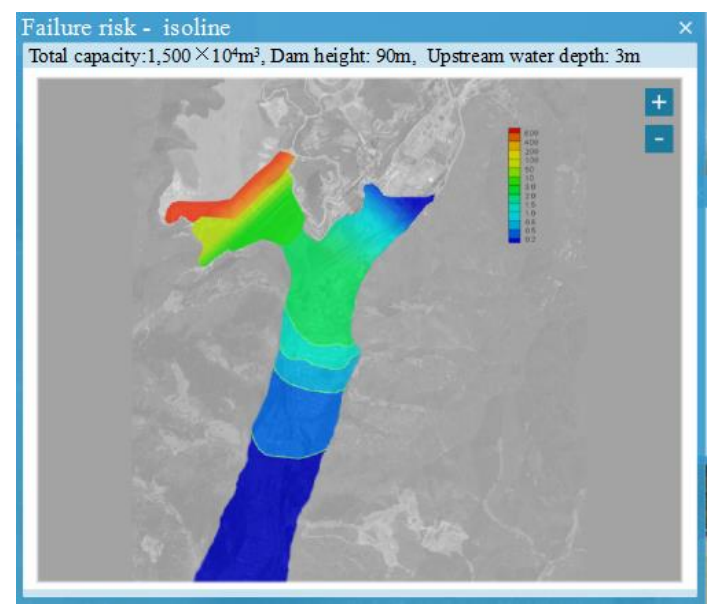

Figure.9 tailings dam dam inundation area

\section{Conclusions}

Taking the more dangerous valley-like tailing pond as an example, this paper establishes a digital tailings pond system which can realize the early warning of the large-scale valley tailings pond. Combined with the features of the terrain, geography and climate of the tailings pond, The case study is carried out on the three aspects of flood control ability of dam tailings, stability of dam and dam failure. conclusion as below:

1) This valley-type digital tailings pond system has been established including online monitoring of tailings ponds, safety management, vehicle positioning and dispatching, emergency management and training, flood control calculation, steady and real-time analysis of dam body, quantitative warning of disasters and risk analysis of dam failure, Equipment operation trend, including 10 subsystems, to achieve the scene display, flood calculation, online monitoring system and early warning, dam stability analysis, safety management, accident risk analysis, system settings and user management, and other 8 major functions .

2) The flood regulation module calculates the flood process curve and drainage displacement of the tailings dam under the condition of one 500-year flood. Through the display of dynamic simulation data and dynamic simulation screen, the operation status and flood prevention capability of the tailings reservoir can be visually inspected, Providing theoretical support for the safety management of tailings flood control phase.

3) By calculating the heavy rain, peak flow and total flood volume of the tailings dam under the condition of 500 years flood, 7.21 flood accident and 24 hours rainfall, the early warning value of tailings reservoir water level is proposed.

4) The software embeds both the finite element method and the discrete element method to calculate the slope stability. The stability of the dam can be analyzed from the macro and micro aspects and the stability coefficient of the dam can be calculated. Taking the discrete element method as an example, the tailings dam was modeled and the dam stability coefficient was calculated to be 1.642 .

5) The dam failure risk analysis module can assess the severity of the dam failure consequences of the tailings dam through the maximum discharge of tailing sand, the depth of downstream debris flow and the inundation area of the dam dam, so as to determine the safety margin of the dam dam and set the warning mark or enclosure in time Small dam may cause damage. 


\section{Acknowledgements}

This research project was made possible through the financial support from the project NO. 2017YFC0804600 by '13th five-year' national key research and development plan, NO. 71373245 by the National Natural Science Foundation of China, and NO.3142017041 by School science and technology fund of North China Institute of Science.

\section{References}

[1] State Administration of Work Safety released. Tailings technical regulations AQ 2006-2005[Z]. 2006. 03. 01 implementation.

[2] Wang Shandong, Zhao Jingcheng. Metal Mine, Vol (2004), p. 46-49.

[3] Li Qingshi, Li Shulin, Chen Jijing. The Chinese journal of geological hazard and control,Vol (2011), p. 99-106.

[4] Liao Wenjing, Huangfu Kailong.Vol ( 2014). p. 158-163.

[5] Dong Shao-yan, Li Quan-ming. China Safety Science and Technology, Vol (2015),p. 78-83.

[6] Cundall P A. A computer model for simulating progressive large scale movements in blocky rock systems $[\mathrm{C}] / /$ Proceeding of the symposium of the international society for rock mechanics, Nancy, 1971, vol I, No.8.

[7] Cundall P A, Strack O D L. Geotechnique, Vo (1979), p. 47-65.

[8] Shi Danda, Deng Yibing, Liu Wenbai, et al. Particulate Discrete Element Method and Its

Application to the Simulation of Sand Behavior (China Communications Press, Beijing, 2016)

[9] Shi Chong,Xu Wei-ya.Particle flow code (PFC2D / 3D) numerical simulation techniques and practice (China Architecture \& Building Press, Beijing, 2015)

[10] ITASCA Consulting Group. PFC2D(Particle Flow Code in 2 Dimensions)User' s Guide ( Itasca Consulting Group, USA, 2002) 